\title{
Population genetic structure of the Neotropical termite Nasutitermes nigriceps (Isoptera: Termitidae)
}

\author{
GRAHAM J . THOMPSON* \& PAUL D. N. HEBERT \\ Department of Zoology, University of Guelph, Guelph, Ontario N1G 2W1, Canada
}

\begin{abstract}
Monogamy and inbreeding are often thought to characterize the breeding system of termite societies. However, few studies have employed genetic markers to ascertain either the genetic structure of single colonies or the extent of local inbreeding. This study employs allozyme analysis to investigate the breeding system of Nasutitermes nigriceps with respect to the number of reproductives contributing to single colonies, and the level of inbreeding within and among local colonies. The majority of the 136 nests examined from three study sites showed patterns of protein polymorphism consistent with their origin from a single mated pair, establishing that monogamy is indeed the predominant mode of reproduction. A small proportion of colonies $(N=7)$ had genotypic frequencies suggesting that offspring were not all full-siblings. The genetic composition of all colonies appeared stable through a one-year interval, suggesting that the observed genetic attributes represent relatively persistent reproductive associations. Wright's (1978) $F$-statistics showed moderate differentiation among study sites, indicative of restricted gene flow and the occurrence of inbreeding at a regional scale. However, mating appeared to be random at single sites as the inferred genotypic frequencies of colony progenitors did not deviate from Hardy-Weinberg expectations, indicating little inbreeding in the study populations.
\end{abstract}

Keywords: allozymes, Isoptera, Jamaica, monogamy.

\section{Introduction}

Theoretical work has demonstrated the important role that kin selection may have in influencing the co-operative behaviour of social organisms. High relatedness within family groups, which is thought to promote colony cohesion and co-operation among nestmates, is dependent on both the dynamics of group formation and mating system (Uyenoyama, 1984). The basic system of monogamy in termites ensures that relatedness among individuals within colonies will, on average, be no lower than that expected of any diploid family. Coupled with a tendency for certain species to inbreed over successive generations (through the production of neotenic reproductives), an increase in relatedness within termite colonies is thought possible (e.g. Hamilton, 1972, 1978). The presence of multiple reproductives, however, can increase the genetic diversity within

${ }^{*}$ Correspondence and present address: School of Genetics and Human Variation, La Trobe University, Bundoora, Victoria 3083, Australia. E-mail: thompson@genome.latrobe.edu.au colonies, and thus jeopardize colony cohesiveness (Williams \& Williams, 1957; West-Eberhard, 1981; Keller, 1995). This is especially true if colonies are established through the co-operation of a genetically diverse group of cofounders (e.g. Thorne, 1985; Roisin, 1993 for Nasutitermes; Darlington, 1985 for Macrotermes). However, if multiple reproductives differentiate from within a colony, the destabilizing effects on relatedness may be offset to some degree as a result of inbreeding (Roisin, 1993). By examining the genetic diversity present within termite colonies, it is possible to make inferences concerning the reproductive status of colonies as well as assess levels of inbreeding.

In the family Termitidae, the developmental pathways which give rise to the reproductive and nonreproductive lines differentiate early and are relatively rigid (Noirot, 1985a) compared to those of most other termite families (Noirot, 1985b). In certain well-studied groups of the Termitidae, however, there is an increasing awareness of variation in both the number and developmental origin of reproduc- 
tives (e.g. Thorne, 1985, Roisin, 1993). In addition to the primary sexuals which arise from flown alates, supplementary or replacement reproductives can develop from unflown alates (adultoid) and, although less frequent in this family, from nymphs (nymphoid), and workers (ergatoid) (Noirot, 1985a; Thorne, 1985). Variation in the reproductive composition of termite colonies has been shown to have ontogenetic and ecological correlates (e.g. Clement, 1981; Darlington, 1985; Thorne, 1985); however, gaining insights into the reproductive status of many termite species is often difficult because of their cryptic nesting habits and the fact that reproductives can be further confined within royal chambers.

Genetic analyses of a small number of nonreproductives can provide much information concerning the breeding system of termite colonies (e.g. Clement, 1981; Reilly, 1987; Luykx, 1993) and, where certain questions are concerned, circumvent the need for destructive sampling. Monogamous breeding systems are, for example, easily identified through allozyme analysis as they yield predictable Mendelian genotypic frequencies. This approach additionally permits study of the temporal stability of the genetic composition of colonies and is especially useful where species have particularly fragile (e.g. Kalotermitidae) or diffuse (e.g. Mastotermitidae, Rhinotermitidae) nesting habits which make direct monitoring difficult. Prior work on the genetic structure of termite colonies has been limited (Clement, 1981; Reilly, 1987; Korman \& Pashley, 1991; Luykx, 1993; Strong \& Grace, 1993), despite the possible role that relatedness may have in promoting the maintenance of isopteran eusociality (Shellman-Reeve, 1997). Genetic studies have, however, provided key insights into levels of relatedness within colonies (Reilly, 1987 for Reticulitermes flavipes, Rhinotermitidae) and have demonstrated geographical variation in mating systems (Clement, 1981 for $R$. santonensis and $R$. lucifugus). Additional studies of the genetic structure of isopteran colonies seem likely to aid in our understanding of eusocial breeding system diversity (Crozier, 1980; Roisin, 1993), in the same way that similar work has contributed to the knowledge of hymenopteran eusociality (e.g. Pamilo \& Varvio-Aho, 1979; Berkelhamer, 1984).

The highly derived genus Nasutitermes is taxonomically diverse with over 180 species (Krishna, 1970) and broadly distributed, being found in six of the eight major biogeographical regions (Pearce \& Waite, 1994). Species in this genus have been relatively well-studied and are known to derive supplementary or replacement reproductives from alates
(Thorne, 1985; Roisin \& Pasteels, 1986a,b), nymphs (Gay \& Calaby, 1970; Fontes \& Terra, 1981) and workers (Noirot, 1985a; Noirot \& Thorne, 1988; Miura \& Matsumoto, 1996), and the number of functional queens and kings can, in some cases, range from one to many hundreds (Roisin \& Pasteels, 1986b). The present study focuses on Nasutitermes nigriceps Haldeman, the most common arboreal termite on Jamaica. Colonies of this species are regularly monogamous (Clarke \& Garraway, 1994), and single nests have been shown to consist of up to 500000 individuals (Clarke, 1993). This study employed allozyme markers to verify the number of reproductives contributing to single nests and to assess levels of inbreeding.

\section{Methods}

\section{Termite collections}

Termites were initially collected from 171 colonies in late April and early May of 1994 from three study sites on Jamaica: Llandovery $\left(18^{\circ} 27^{\prime} \mathrm{N}, 77^{\circ} 16^{\prime} \mathrm{W}\right)$, Negril $\left(18^{\circ} 21^{\prime} \mathrm{N}, 78^{\circ} 20^{\prime} \mathrm{W}\right)$ and Millbank $\left(18^{\circ} 02^{\prime} \mathrm{N}\right.$, $76^{\circ} 24^{\prime} \mathrm{W}$ ) where 78,71 and 22 colonies were sampled, respectively. Colonies were marked and mapped, and 68 colonies were resampled in May 1995 from the Llandovery and Negril sites. Nests are constructed below the tree canopy and are usually well spaced (Clarke, 1993). An effort was made to resample all colonies in 1995 whose genotypic ratios did not initially conform to Mendelian expectations, but otherwise included a random subset of the previously sampled colonies. Collections were made by breaking open the arboreal carton nests and cryopreserving (in liquid nitrogen) $\approx 100$ live individuals from each colony. Collections did not discriminate between small or large workers, or soldiers.

\section{Allozymes}

All electrophoresis was carried out on cellulose acetate gels using standard methods (Hebert \& Beaton, 1993). Forty-eight individuals, representing a single individual from each of 16 different colonies per site were used to screen for polymorphisms at 25 loci: aconitase hydratase (Acon) (EC 4.2.1.3), alcohol dehydrogenase (Adh) (EC 1.1.1.1), aldehyde oxidase $(A o)$ (EC 1.2.3.1), arginine phosphokinase (Apk) (EC 2.7.3.3), carboxylesterase (Est, two loci) (EC 3.1.1.1), fumarate hydratase (Fum) (EC 4.2.1.2), glucose-6-phosphate dehydrogenase (G6pdh) (EC 1.1.1.49), glycerol-3-phosphate dehydrogenase (Gpdh, two loci) (EC 1.1.1.8), isocitrate dehydrogenase (Idh, two loci) (EC 1.1.1.42), lactate dehydro- 
genase ( $L d h)$ (EC 1.1.1.27), malate dehydrogenase $(M d h)$ (EC 1.1.1.37), malate dehydrogenase $\mathrm{NADP}^{+}$ (Me) (EC 1.1.1.40), mannose-6-phosphate isomerase (Mpi) (EC 5.3.1.8), peptidase (Pep-B) (EC 3.4.13, dipeptide used L-phenylalanyl-t-proline), (Рep-C, two loci) (dipeptide used L-leucyl-L-alanine), phosphoglucomutase (Pgm) (EC 5.4.2.2), 6-phosphogluconate dehydrogenase (6Pgdh) (EC 1.1.1.44), phosphoglucoisomerase (Pgi) (EC 5.3.1.9), trehalase (two loci) (EC 3.2.1.28) and xanthine dehydrogenase $(X d h)$ (EC 1.1.1.204). This initial screening identified two loci which were polymorphic, $M d h$ and Pep-C. Subsequent screening focused on these two loci and ordinarily involved the analysis of 48 individuals from each collection of a colony. However, when the first 24 individuals from a collection were homozygous, no further individuals were analysed at that locus. $R_{\mathrm{f}}$ values were determined for alleles at the two polymorphic loci.

\section{Data analysis}

Decisions concerning the mating system of $N$. nigriceps were made by determining the genotypic composition of nests at the $M d h$ and Pep loci. If individual nests contain offspring from a single pair of mated individuals, then genotypic frequencies within should approximate Mendelian ratios. Alternatively, if a nest contains offspring from a number of reproductives, then genotypic frequencies will ordinarily deviate from Mendelian expectations at one or more loci. Nests which were polymorphic for at least one locus (136 of the 171) were tested against Mendelian expectations using a chi-squared test $(\alpha=0.05)$ and applying a sequential Bonferroni correction for multiple comparisons (Rice, 1989). The remaining colonies, which included only individuals homozygous at both loci, could not be tested in this fashion and were excluded from this part of the analysis.

To examine the issue of reproductive stability, 68 nests were reanalysed in the same manner after an interval of one year to assess the temporal stability of their genotypic composition. Consistency of genotypic frequencies through time would be expected if the reproductive composition of colonies remained unchanged, whereas a shift of genotypic frequencies would suggest that changes to the reproductive composition of colonies had occurred. This approach is based upon the presumption that a substantial proportion of workers and soldiers will be renewed over this interval. The workers and soldiers of central-site nesters (sensu Abe, 1987), such as $N$. nigriceps, have been shown to be relatively short-lived, possibly because of the high risks associated with exposure when foraging away from the nest. Where it has been examined, workers and soldiers of this life-type live for an average of 3-6 months (Josens, 1982 for Trinervitermes; Darlington, 1991 for Macrotermes).

Mean allele frequencies $(p)$ of populations were determined at each of the three study sites by calculating the allele frequencies of single nests, and subsequently averaging across all nests. This procedure yields an unbiased estimate of population allele frequencies in instances where many individuals have been sampled per nest. In order to determine the number of nests required to estimate allele frequencies accurately, the relationship between the standard error of the estimate and the number of nests analysed was determined. Estimates of $p$ were considered accurate when the standard error of $p$ was less than 0.05 .

The variance in allele frequencies among sites was used to generate a measure of population structure using Wright's (1978) $F$-statistics. Calculations were performed with version 1.7 of BIOsys-1 (Swofford \& Selander, 1989) to ascertain the degree of differentiation among sites with respect to allele frequencies $\left(F_{\mathrm{ST}}\right)$. In addition, the genotypes of nest progenitors, inferred from offspring genotype frequencies, were used to ascertain if random mating occurred at each site by comparing the parental frequencies to those expected under Hardy-Weinberg equilibrium. This was assessed for each locus at each site, using a chi-squared test $(\alpha=0.05)$. The few nests which showed genotypic arrays that differed significantly from Mendelian expectations were not included in this part of the analysis, as their parental genotypes could not be ascertained.

\section{Results}

\section{Allele frequencies}

The mean frequencies of the commoner allele at each of the three sites ranged from 0.75-0.97 at Pep and from 0.49-1.00 at Mdh (Table 1). Nests at Millbank showed the least diversity, as both loci were essentially monomorphic. The uncertainty in allele frequency estimates was substantial when few nests were sampled at a site. However, by sampling 20 or more nests, the standard error of the estimate in allele frequencies was reduced to 0.05 or less.

\section{Genotypic ratios}

Nasutitermes soldiers are all male and heterogametic (Noirot, 1985a; Vincke \& Tilquin, 1978)

(C) The Genetical Society of Great Britain, Heredity, 80, 48-55. 
whereas workers are either male or female. Because sex-linkage could lead to a differential genotypic frequency between these two nonreproductive castes, caste membership was recorded prior to allozyme analysis. No association was found between caste and genotypic frequencies at either Pep $(G=2.39, P>0.05)$ or $M d h(G=2.82, P>0.05)$ indicating that both loci are autosomal. Given the lack of sex-linkage, maximum likelihood estimates of genotypic frequencies in single nests were obtained by pooling individuals irrespective of caste.

Thirty-five of the 171 nests were homozygous at both loci and 21 of these nests were found at Millbank. At least one of the two loci was polymorphic for the remaining 136 nests, allowing for a test against Mendelian expectations. The number of nests with genotypic frequencies that differed significantly from Mendelian expectations, assuming a monogamous mating, varied among sites (Table 2). Genotypic frequencies in three (out of 48) Llandovery nests deviated significantly from Mendelian expectations at the Pep locus, as did four (of 50) at

Table 1 Mean allele frequencies of nests of Nasutitermes nigriceps at three sites on Jamaica at the peptidase (Pep) and malate dehydrogenase $(M d h)$ loci. Alleles at each locus are designated by their $R_{\mathrm{f}}$ value in relation to the more common allele

\begin{tabular}{lcccc}
\hline Locus & Allele & $\begin{array}{c}\text { Llandovery } \\
N=78\end{array}$ & $\begin{array}{c}\text { Negril } \\
N=71\end{array}$ & $\begin{array}{c}\text { Millbank } \\
N=22\end{array}$ \\
\hline Pep & 1.00 & 0.753 & 0.885 & 0.965 \\
& 0.65 & 0.247 & 0.115 & 0.035 \\
Mdh & 1.00 & 0.752 & 0.486 & 1.0 \\
& 0.90 & 0.248 & 0.514 & 0.0 \\
\hline
\end{tabular}

the $M d h$ locus. One nest (of 63) at Negril showed a significant deviation at the $M d h$ locus, whereas none (of 21) was deviant at the Pep locus. Only one polymorphic nest was detected at Millbank, and its genotypic frequencies conformed to Mendelian expectations. Because of the low level of allelic variation at the Millbank location, these colonies were not included in this part of the analysis.

Genotypic frequencies were re-examined in 68 nests after a one-year interval. Of 64 monogamous nests resampled in 1995, all retained the same genotypic frequencies as the year before. Of four nonmonogamous nests resampled, three sustained the same pattern of deviation from Mendelian expectations (Table 2).

\section{Population structure}

Table 3 provides a summary of the different parental genotype combinations inferred from nest genotype ratios at both polymorphic loci. The frequencies of parental genotypes at local sites were not significantly different from Hardy-Weinberg expectations at either locus $\left(P>0.05\right.$, Llandovery $\chi_{P e p}^{2}=2.82$, $\chi_{\text {Mdh }}^{2}=1.69$; Negril $\chi_{\text {Pep }}^{2}=3.72, \chi_{\text {Mdh }}^{2}=2.57$; Millbank $\chi_{\text {Pep }}^{2}=1.47, \chi_{\text {Mdh }}^{2}=$ no test). Wright's $F$-statistics did, however, show moderate differentiation in allele frequency among the three sites $\left(F_{\text {STPep }}=0.033\right.$; $F_{\text {STMdh }}=0.151 ;$ mean $F_{\text {ST }}=0.107$ ).

\section{Discussion}

The analysis of genetic variation within and among termite colonies can provide insights into their social structure. The effectiveness of allozyme analysis as a monitor of colony structure is necessarily dependent on the presence of polymorphic loci. Overall, the

Table 2 Nests of Nasutitermes nigriceps with genotypic frequencies that deviated significantly from Mendelian expectations for a monogamous pair of reproductives

\begin{tabular}{|c|c|c|c|c|c|c|c|c|c|c|c|c|}
\hline \multirow[b]{3}{*}{ Nest } & \multicolumn{6}{|c|}{ Pep genotypes } & \multicolumn{6}{|c|}{$M d h$ genotypes } \\
\hline & \multicolumn{3}{|c|}{1994} & \multicolumn{3}{|c|}{1995} & \multicolumn{3}{|c|}{1994} & \multicolumn{3}{|c|}{1995} \\
\hline & $f f$ & $f_{S}$ & ss & $f f$ & $f_{s}$ & ss & $f f$ & $f_{s}$ & ss & $f f$ & $f_{s}$ & ss \\
\hline L16 & 12 & 25 & 5 & 20 & 17 & 9 & 32 & 12 & $1^{*}$ & 28 & 17 & $2^{*}$ \\
\hline L24 & 34 & $11^{*}$ & & 30 & 13 & & & 27 & 18 & & 27 & 20 \\
\hline L41 & 44 & & & & Not colle & & 9 & $35^{*}$ & & & Not col & \\
\hline L65 & 8 & 33 & 4 & & Not colle & & 23 & 22 & $1^{*}$ & & Not col & \\
\hline L71 & 38 & $6^{*}$ & & 39 & $9^{*}$ & & 23 & 20 & $1^{*}$ & 24 & 16 & 1 \\
\hline L81 & 10 & 10 & $22^{*}$ & 15 & 7 & $21^{*}$ & & 22 & & & 48 & \\
\hline N56 & 23 & 21 & & & Not colle & & 4 & 15 & $24 *$ & & Not col & \\
\hline
\end{tabular}

${ }^{*} P<0.05$.

(C) The Genetical Society of Great Britain, Heredity, 80, 48-55. 
Table 3 Summary of parental genotypes for monogamous nests of Nasutitermes nigriceps inferred from offspring genotype frequencies at two loci at three sites in Jamaica

\begin{tabular}{|c|c|c|c|c|c|c|c|c|c|}
\hline \multirow{2}{*}{\multicolumn{3}{|c|}{ Nest genotype ratio }} & \multirow{3}{*}{$\begin{array}{l}\text { Inferred } \\
\text { parental } \\
\text { genotype }\end{array}$} & \multicolumn{6}{|c|}{ Number of nests observed per site } \\
\hline & & & & \multicolumn{2}{|c|}{ Llandovery } & \multicolumn{2}{|c|}{ Negril } & \multicolumn{2}{|c|}{ Millbank } \\
\hline$f f$ & $f_{s}$ & $s s$ & & Pep & $M d h$ & Pep & $M d h$ & Pep & $M d h$ \\
\hline \multirow[t]{3}{*}{1} & & & $f f \times f f$ & 25 & 22 & 46 & 1 & 20 & 22 \\
\hline & 1 & & $f f \times s s$ & 4 & 4 & 4 & 5 & 1 & 0 \\
\hline & & 1 & $s s \times s s$ & 0 & 0 & 0 & 2 & 0 & 0 \\
\hline \multirow[t]{2}{*}{1} & 1 & & $f f \times f_{s}$ & 25 & 34 & 11 & 18 & 1 & 0 \\
\hline & 1 & 1 & $f s \times s s$ & 0 & 3 & 0 & 24 & 0 & 0 \\
\hline 1 & 2 & 1 & $f_{s} \times f_{s}$ & 16 & 7 & 6 & 17 & 0 & 0 \\
\hline
\end{tabular}

proportion of loci that was polymorphic in $N$. nigriceps was not high - only 8 per cent. This is the lowest level of polymorphism so far reported for any termite species; values in other studies range between 12 per cent in Coptotermes formosanus (Strong \& Grace, 1993), 17 per cent in Incisitermes schwarzi (Santos \& Luykx, 1985) and C. formosanus (Korman \& Pashley, 1991), 40 per cent in Reticulitermes flavipes (Reilly, 1987), 52 per cent in Reticulitermes sp. (Clement, 1981) and 65 per cent in Zootermopsis sp. (Korman et al., 1991).

Despite the limited number of polymorphic allozyme loci, our work was able to show that most nests of $N$. nigriceps have genotypic frequencies which approximate Mendelian expectations and verifies that monogamy (monogyny and monoandry) is the predominant mode of reproduction for this species. This interpretation of the breeding system of $N$. nigriceps is in agreement with Clarke \& Garraway (1994) who found no more than one pair of reproductives in nests which had at least one reproductive. Further, the present study indicates that there is little to no turnover in the reproductive composition of colonies, at least over the interval of one year. Our results do show, however, that at least 5 per cent (seven of 136) of nests of $N$. nigriceps contain offspring derived from more than one breeding pair, as indicated by their deviation from Mendelian expectations at one or more loci.

Although our results suggest that only a small percentage of nests of $N$. nigriceps contain mixed broods, it is important to emphasize that multiple male or female parents of the same genotype would not be detected by our analysis. For example, a colony consisting of a single queen and several males with identical genotypes at both polymorphic loci will be indistinguishable from those with a single male. Given that only two loci were examined in this species, our estimates of the incidence of deviant nests are conservative.

Besides the simultaneous contribution of more than one reproductive pair to nest offspring composition (either from pleometrosis - the co-operation of a genetically diverse group of alates - or the in situ co-operation of supplemental or multiple sibling replacements), deviations from Mendelian ratios may occur from reproductive turnover, where a replacement reproductive takes over from the original of the same sex (i.e. serial monogamy). When 68 nests were resampled after a one-year interval, however, genotype frequencies were consistent from one year to the next. All nests with Mendelian ratios that were resampled, again yielded the same Mendelian ratios. Of the four deviant nests re-examined in 1995, three showed persistent deviations from Mendelian ratios. Moreover, the direction of these changes, in terms of either a homozygote or heterozygote excess, was the same from one year to the next. This consistent pattern of kin structure observed within colonies makes it unlikely that the observed deviations from expected ratios are the result of reproductive replacement within a monogamous system. An interval of this duration would probably provide sufficient time for a substantial renewal of offspring (workers and soldiers) and would have been detected by our analysis. Therefore, the deviations are more likely to arise from multiple reproductives contributing offspring to a single nest in a more continuous fashion. Our genetic data do not rule out multiple reproductives in a single nest, but, as single colonies of this species may occupy more than one nest (Clarke \& Garraway, 1994), the deviant kin structure is more likely to result from the mixing of offspring from connected daughter nests which have since developed reproductives of their own.

(c) The Genetical Society of Great Britain, Heredity, 80, 48-55. 
Our sampling regime did not discriminate among colonies based on their size or apparent maturity. Hence, if supplementary or replacement reproductives of $N$. nigriceps are generated at a particular stage of colony development, it should have led to a change in genotypic composition that would have been detected by this cross-sectional analysis. The stability of genotypic composition of nests over a one-year interval suggests instead that reproductives ordinarily remain active for many seasons.

In termites, inbreeding may occur when colonies are composed of related individuals which remain genetically isolated from other such colonies for several generations (Clement, 1981; Reilly, 1987). Alternatively, inbreeding may occur at colony foundation following the nonrandom assortment of flown alates. In monogamous species, the reproductives that appear in a mature nest at the time of swarming are full-siblings. Because many termites are weak fliers and may not travel far from the original colony, and because different colonies may swarm asynchronously (Nutting, 1969), it is possible that new colonies may occasionally originate from sibling pairs, rather than intercolony matings. Nonrandom mating of this sort would be reflected in the genetic composition of populations, and would, if intense, lead to allele fixation within colonies. The present study has, however, provided clear evidence of random mating by colony progenitors at single sites, establishing that the pairing of reproductives following the dispersive flight is random within local populations of $N$. nigriceps. However, the results of our $F$-statistics analysis indicate that allelic differentiation among the three sites is significant (Wright, 1978), suggesting that the dispersal of alates of $N$. nigriceps is limited on a regional scale.

Termites may have difficulty in long-distance dispersal, because pairs must remain together after the flight in order to found a new colony, contrasting with the situation in Hymenoptera where females can disperse after insemination. The tendency for localized colonization is further suggested by the pattern of allele frequency variation apparent among the three sites. Specifically, the mean allele frequency of local populations approximated 0.5 , 0.75 or 1.0 in five of six cases. This distribution of allele frequencies is most easily achieved if local metapopulations are the progeny of a single ancestral monogamous colony. The analysis of allele frequencies at a higher level of spatial resolution could provide a better sense of both the number of founder sites across Jamaica, and of diffusion from these sites.

Although most nests of $N$. nigriceps are monoga- mous, some appear to contain the offspring of multiple reproductives. A few other congeneric species exhibit more extensive levels of polygamy (Thorne, 1984; Roisin \& Pasteels, 1986b) generated through the full range of developmental pathways (Thorne, 1982; Roisin \& Pasteels, 1986a). This includes $N$. costalis (Roisin \& Pasteels, 1986b) which is sympatric with $N$. nigriceps throughout parts of its range on Jamaica. The adaptive significance of a variable breeding programme in termites remains unclear (Roisin, 1993), and factors influencing the number of reproductives probably vary among taxa.

As all termites are eusocial, it is impossible to study directly the factors involved in the initial adoption of isopteran eusociality. It is, however, possible to study the selective forces which currently act to maintain social cohesion and which account for variation in the reproductive composition of colonies. Cases such as $N$. costalis, whose colonies can approach 100 functional reproductives (Roisin \& Pasteels, 1986b), merit investigation. It is, for example, possible that transitions to polygamy occur following extreme population bottlenecks which deplete a species of genetic variability. Individuals which, as a result, share an increased proportion of alleles (compared to that of the recent mother population) may show, in a kin affiliated manner, an increased tolerance for coexisting reproductives and their respective broods. Comparative studies examining the levels of genetic diversity and the breeding system of termites are essential to understand the factors important in modulating colony structure and should lead to a more complete understanding of termite eusociality.

\section{Acknowledgements}

We thank Drs P. A. Clarke and E. Garraway (University of West Indies, Kingston, Jamaica) for advice on termite collections in Jamaica. T. Crease, T. L. Finston, G. Otis and R. H. Crozier provided helpful criticisms on earlier drafts of the manuscript. This research was supported by a grant from the Natural Sciences and Engineering Research Council of Canada to P.D.N.H.

\section{References}

ABE, T. 1987. Evolution of life types in termites. In: Kawano, S., Connell, J. J. H. and Hidaka, T. (eds) Evolution and Coadaptation in Biotic Communities, pp. 125-148. University of Tokyo Press, Tokyo.

BERKELHAMER, R. C. 1984. An electrophoretic analysis of queen number in three species of dolichoderine ants. Insectes Soc., 31, 132-141. 
ClARKE, P. A. 1993. Alate production in colonies of Nasutitermes nigriceps and Nasutitermes costalis (Isoptera: Termitidae) in Jamaica and Trinidad. Sociobiology, 23, 167-174.

Clarke, P. A. AND Garraway, E. 1994. Development of nests and composition of colonies of Nasutitermes nigriceps (Isoptera: Termitidae) in the mangroves of Jamaica. Flor. Entomol., 77, 272-280.

Clement, J. L. 1981. Enzymatic polymorphism in the European populations of various Reticulitermes species (Isoptera). In: Howse, P. E. and Clement, J. L. (eds) Biosystematics of Social Insects, pp. 49-62. Academic Press, New York.

CROZIER, R. H. 1980. Genetical structure of social insect populations. In: Markl, H. (ed.) Evolution of Social Behavior: Hypotheses and Empirical Tests, pp. 129-146. Verlag Chemie, Weinheim.

DARLINGTON, J. P. E. C. 1985 . Multiple primary reproductives in the termite Macrotermes michaelseni (Sjöstedt). In: Watson, J. A. L., Okot-Kotber, B. M. and Noirot, C. (eds) Caste Differentiation in Social Insects: Current Themes in Tropical Science, vol. 3, pp. 187-200. Pergamon Press, Oxford.

DARlington, J. P. E. C. 1991. Turnover in the populations within mature nests of the termite Macrotermes michaelseni in Kenya. Insectes Soc., 38, 251-262.

FONTES, L. R. AND TERRA, P. S. 1981. A study on the taxonomy and biology of the Neotropical termite Nasutitermes aquilinus (Isoptera, Termitidae, Nasutitermitinae). Rev. bras. Ent., 25, 171-183.

GAY, F. J. AND CALABY, J. H. 1970. Termites of the Australian region. In: Krishna, K. and Weesner, F. M. (eds) Biology of Termites, vol. 2, pp. 393-448. Academic Press, New York.

HAMilton, w. D. 1972. Altruism and related phenomena, mainly in the social insects. Ann. Rev. Ecol. Syst., 3, $193-232$.

HAMilton, w. D. 1978. Evolution and diversity under bark. In: Mound, L. A. and Waloff, N. (eds) Diversity of Insect Faunas, pp. 154-175. Symposia of the Royal Entomological Society of London, no. 9. Blackwell Scientific Publications, Oxford.

HEBERT, P. D. N. AND BEATON, M. J. 1993. Methodologies for Allozyme Analysis using Cellulose Acetate Electrophoresis. Helena Laboratories, Beaumont, TX.

JOSENS, G. 1982. Le bilan énérgétique de Trinervitermes geminatus Wasmann (Termitidae: Nasutitermitinae): 1. Measure de biomass, d'equivalents énérgétiques, de longévité et de production en laboratoire. Insectes Soc., 29, 295-307.

KELLER, L. 1995. Social life: the paradox of multiple-queen colonies. Trends Ecol. Evol., 10, 355-360.

KORMAN, A. K. AND PASHLEY, D. P. 1991. Genetic comparisons among U.S. populations of Formosan subterranean termites. Sociobiology, 9, 41-50.

KORMAN, A. K., PASHLEY, D. P., HAVERTY, M. I. AND LA FAGE, J. P. 1991. Allozymic relationships among cuticular hydrocarbon phenotypes of Zootermopsis species
(Isoptera: Termopsidae). Ann. Entomol. Soc. Am., 84, 1-9.

KRISHNA, K. 1970. Taxonomy, phylogeny, and distribution of termites. In: Krishna, K. (ed.) Biology of Termites, vol. 2, pp. 127-152. Academic Press, New York.

LUYKX, P. 1993. Allozyme markers and formal Mendelian genetics of the termite Incisitermes schwarzi (Isoptera: Kalotermitidae). Sociobiology, 21, 185-192.

MIURA, T. AND MATSUmoto, T. 1996. Ergatoid reproductives in Nasutitermes takasagoensis (Isoptera: Termitidae). Sociobiology, 27, 223-238.

NOIROT, C. $1985 \mathrm{a}$. The caste system in higher termites. In: Watson, J. A. L., Okot-Kotber, B. M. and Noirot, C. (eds) Caste Differentiation in Social Insects, pp. 75-86. Pergamon Press, Oxford.

NOIROT, C. 1985b. Pathways of caste development in the lower termites. In: Watson, J. A. L., Okot-Kotber, B. M. and Noirot, C. (eds) Caste Differentiation in Social Insects, pp. 41-58. Pergamon Press, Oxford.

NOIROT, C. AND THORNE, B. L. 1988. Ergatoid reproductives in Nasutitermes columbicus (Isoptera, Termitidae). J. Morphol., 195, 83-93.

NUTtiNG, w. L. 1969. Flight and colony foundation. In: Krishna, K. and Weesner, F. M. (eds) Biology of Termites, vol. 1, pp. 233-282. Academic Press, New York.

PAMILO, P. AND VARVIO-AHO, S.-L. 1979. Genetic structure of nests in the ant Formica sanguinea. Behav. Ecol. Sociobiol., 6, 91-98.

PEARCE, M. J. AND WAITE, B. S. 1994. A list of termite genera (Isoptera) with comments on taxonomic changes and regional distribution. Sociobiology, 3, 247-263.

REILLY, L. M. 1987. Measurement of inbreeding and average relatedness in a termite population. Am. Nat., 130, 339-349.

RICE, W. R. 1989. Analyzing tables of statistical tests. Evolution, 43, 223-225.

ROISIN, Y. 1993. Selective pressures on pleometrosis and secondary polygyny: a comparison of termites and ants. In: Keller, L. (ed.) Queen Number and Sociality in Insects, pp. 402-421. Oxford University Press, New York.

ROISIN, Y. AND PASTEElS, J. M. 1986a. Replacement of reproductives in Nasutitermes princeps (Desneux) (Isoptera: Termitidae). Behav. Ecol. Sociobiol., 18, 437-442.

ROISIN, Y. AND PASTEELS, J. M. 1986b. Reproductive mechanisms in termites: polycalism and polygyny in Nasutitermes polygynous and $N$. costalis. Insectes Soc., 33, 149-167.

SANTOS, O. AND LUYKX, P. 1985. Homozygosity for sex-linked genes in males of the termite Incisitermes schwarzi. Biochem. Genet., 23, 729-740.

SHELLMAN-REEVE, J. s. 1997. The spectrum of eusociality in termites. In: Crespi, B. J. and Choe, S. C. (eds) The Evolution of Social Behaviour in Insects and Arachnids, pp. 52-93. Cambridge University Press, Cambridge.

STRONG, K. L. AND GRACE, J. K. 1993. Low allozyme varia- 
tion in Formosan subterranean termite (Isoptera: Rhinotermitidae) colonies in Hawaii. Pan-Pacific Entomol., 69, 51-56.

SWOFFORD, D. L. AND SElANDER, R. B. 1989. BIOSYS-1. $A$ computer program for the analysis of allelic variation in population genetics and biochemical systematics. Release 1.7. University of Illinois, Urbana, IL.

THORNE, B. L. 1982. Reproductive plasticity in the Neotropical termite Nasutitermes corniger. In: Jaisson, P. (ed.) Social Insects in the Tropics, vol. 1, pp. 22-29. Université Paris-Nord, Paris.

Thorne, в. L. 1984. Polygyny in the Neotropical termite Nasutitermes corniger: life history consequences of queen mutualism. Behav. Ecol. Sociobiol., 14, 117-136.

THORNE, B. L. 1985. Termite polygyny: the ecological dynamics of queen mutualism. In: Hölldobler, B. and Lindauer, M. (eds) Experimental Behavioral Ecology and Sociobiology, pp. 325-342. Fischer Verlag, Stutgart.
UYENOYAMA, M. 1984. Inbreeding and the evolution of altruism under kin selection: effects on relatedness and group structure. Evolution, 38, 778-795.

VINCKE, P. P. AND TILQUin, J. P. 1978. A sex-linked ring quadrivalent in Termitidae (Isoptera). Chromosoma, 67, 151-156.

WEST-EBERHARD, M. J. 1981. Intragroup selection and the evolution of insect societies. In: Alexander, R. D. and Tinkle, D. W. (eds) Natural Selection and Social Behavior: Recent Research and New Theory, pp. 3-17. Chiron Press, New York.

WILLIAMS, G. C. AND WILLIAMS, D. C. 1957. Natural selection of individually harmful social adaptations among sibs with special reference to social insects. Evolution, 11, 32-39.

WRIGHT, s. 1978. Evolution and the Genetics of Populations, vol. 4, Variability Within and Among Populations. University of Chicago Press, Chicago. 